\title{
Cyanopeptolin 954, a Chlorine-Containing Chymotrypsin Inhibitor of Microcystis aeruginosa NIVA Cya 43
}

\author{
Eric von Elert, ${ }^{* \dagger}{ }^{\dagger}$ Lukas Oberer, ${ }^{\ddagger}$ Petra Merkel,${ }^{\dagger}$ Thomas Huhn,,${ }^{\S}$ and Judith F. Blom ${ }^{\perp}$ \\ Limnological Institute, University of Konstanz, 78457 Konstanz, Germany, Novartis Pharma AG, Preclinical Research, \\ CH-4002 Basel, Switzerland, Institute of Organic Chemistry, University of Konstanz, 78457 Konstanz, Germany, and \\ Limnological Station, Institute of Plant Biology, University of Zürich, Seestrasse 187, 8802 Kilchberg, Switzerland
}

\begin{abstract}
A new depsipeptide, cyanopeptolin 954 (1), was isolated from the freshwater cyanobacterium Microcystis aeruginosa NIVA Cya 43. The structure of the compound was elucidated by chemical and spectroscopic analyses, including 2D NMR and GC-MS of the hydrolysate. The major structural differences compared to previously characterized heptadepsipeptides of Microcystis are the replacement of the basic amino acid in position 4 by L-leucine, the presence of L-phenylalanine in position 6 , and the uncommon residue 3 '-chloro- $N$-Me-L-tyrosine in position 7 . Cyanopeptolin 954 inhibited chymotrypsin with an $\mathrm{IC}_{50}$ value of $45 \mathrm{nM}$. Nostopeptin BN920, formerly isolated from the cyanobacterium Nostoc, ${ }^{1}$ was isolated from the same strain of Microcystis, and a cis amide bond between Phe (6) and N-Me-Tyr (7) was shown. Nostopeptin BN920 inhibited chymotrypsin with an $\mathrm{IC}_{50}$ value of $31 \mathrm{nM}$.
\end{abstract}

The vast majority of the toxic cyanobacterial waterblooms worldwide are formed by cyanobacteria of the genus Microcystis. In most cases toxicity in Microcystis is due to the synthesis of hepatotoxins of the microcystin family. However, the extensive search for new protease inhibitors in recent years has revealed that only about $50 \%$ of the Microcystis water blooms show hepatotoxicity to mammals and other animals, but almost all contain protease inhibitors. ${ }^{2,3}$ It can be hypothesized that under natural conditions these inhibitors may act as important defense molecules against potential grazers of Microcystis. Several groups of inhibitors of serine proteases were isolated from toxic and nontoxic Microcystis species. The most abundant are depsipeptides that contain the modified amino acid 3-amino6-hydroxy-2-piperidone (Ahp). Considering Ahp as a derivative of glutamate, hexa-, hepta-, and octadepsipeptides have been found, all of which contain a six-amino-acidmembered ring with a lactone structure between the C-terminus and the hydroxy group of threonine. In all Ahpcontaining depsipeptides in Microcystis either isoleucine or valine is the C-terminal amino acid, and the amino group of threonine or the $\mathrm{N}$-terminal amino acid of the side chain is linked to a short-chain carboxylic acid. The amino acid adjacent to the $\mathrm{C}$-terminus is an $\mathrm{N}$-methylated aromatic amino acid (Phe, Tyr, ring-chlorinated $\mathrm{Tyr}^{4}$, kynurenine ${ }^{5}$ ) or an N-methylated heteroaromatic amino acid $\left(\operatorname{Trp}^{5-7}\right)$. Depsipeptides of Microcystis that show these basic structures haven been labeled cyanopeptolins, ${ }^{8}$ micropeptins,${ }^{9}$ aeruginopeptins, ${ }^{6}$ and microcystilides. ${ }^{10}$ Following the reasoning of Bister at al. ${ }^{11}$ that the cyanopeptolins were the first variants to be reported with a complete stereochemistry, we use this trivial name for the new compound cyanopeptolin 954 .

\section{Results and Discussion}

Bioassay-guided fractionation of the extract of Microcystis NIVA Cya 43 by solid-phase extraction and subse-

\footnotetext{
* To whom correspondence should be addressed. (E.v.E.) Phone: +49-7531-882935. Fax: +49-7531-883533. E-mail: eric.vonelert@uni-konstanz.de.

Limnological Institute, University of Konstanz.

\$ Novartis Pharma.

§ Institute of Organic Chemistry, University of Konstanz.

${ }^{\perp}$ Limnological Station, University of Zürich.
}

quent separation on a reversed-phase HPLC resulted in two compounds displaying inhibitory activity against chymotrypsin. Upon analysis with LC-ESIMS, the MS/MS fragmentation pattern of one compound indicated the presence of one chlorine and suggested it to be an as yet unknown cyanopeptolin. The new compound, cyanopeptolin 954, exhibited a quasi molecular ion $[\mathrm{M}+\mathrm{Na}]^{+}$at $\mathrm{m} / \mathrm{z}$ 977.5. The second compound exhibited a quasi molecular ion $[\mathrm{M}+\mathrm{Na}]^{+}$at $\mathrm{m} / z$ 943.5, which suggested it to be identical to the depsipeptide nostopeptin BN920 previously reported of the cyanobacterial genus Nostoc. ${ }^{1}$ The peptide nature of cyanopeptolin 954 and nostopeptin BN920 was suggested by amino acid analysis of the hydrolysate that indicated the presence of Val, Leu, Glu, Thr, and Phe in both compounds and the presence of chloro-N-Me Tyr in cyanopeptolin 954 and of N-Me Tyr in nostopeptin BN920.

High-resolution electrospray mass spectrometry $\left(\mathrm{ESI}^{+}\right.$MS) of the sodium adduct of cyanopeptolin 954 led to a base peak of $\mathrm{m} / \mathrm{z}$ 977.4141, yielding the molecular formula $\mathrm{C}_{46} \mathrm{H}_{63} \mathrm{~N}_{8} \mathrm{O}_{12} \mathrm{ClNa}$ with a deviation of $0.5 \mathrm{ppm}$ from the calculated exact mass. Therefore, uncharged cyanopeptolin 954 has the molecular formula $\mathrm{C}_{46} \mathrm{H}_{63} \mathrm{~N}_{8} \mathrm{O}_{12} \mathrm{Cl}$. The isotopic distribution of the ions indicated the presence of chlorine. The following $\mathrm{N}$-acylated amino acids could be established from ${ }^{1} \mathrm{H}$ and ${ }^{13} \mathrm{C} 1 \mathrm{D}$ and homo- and heteronuclear $2 \mathrm{D} \mathrm{NMR}$ spectra of cyanopeptolin 954 (Table 1): Glu, Leu, Val, 3-amino-6-hydroxy-2-piperidone (Ahp), O-acylated Thr, $\mathrm{N}$-alkylated Phe, and N-methylated 3'-chloro-Tyr. NMR data of Ahp in cyanopeptolin 954 were consistent with previously published data of Ahp in other depsipeptides (see Supporting Information). The structure of N-methylated 3'-chloro-Tyr was deduced from the 2D NMR spectrum and confirmed by comparison of the NMR data with those published from scyptolins $\mathrm{A}$ and $\mathrm{B}^{12}$ and micropeptins 478-A and -B. ${ }^{13}$ An additional singlet in the ${ }^{1} \mathrm{H}$ spectrum was identified as an $\mathrm{N}$-acetyl group. ROESY correlations (Table 1) from Phe (6) to Ahp (5) confirm that the nitrogen of Phe (6) is part of the Ahp moiety with both amino acids forming the typical hemiaminal structure.

The amino acid sequence of cyanopeptolin 954 could be deduced from sequential ROESY correlations (NOE) like $\alpha-\mathrm{N}_{i, i+1}, \beta-\mathrm{N}_{i, i+1}, \delta-\beta_{i, i+1}$, or $\alpha-\alpha_{i, i+1}$. The $\alpha-\alpha$ NOE from Phe (6) to $N$-methyl-3'-chloro-Tyr (7) indicated a cis amide 
Table 1. NMR Data of Cyanopeptolin 954 (1) in DMSO- $d_{6}$

\begin{tabular}{|c|c|c|c|c|c|}
\hline $\begin{array}{l}\text { amino } \\
\text { acid }\end{array}$ & position & $\delta_{\mathrm{C}}$ & $\delta_{\mathrm{H}}$ & $\begin{array}{c}\text { selected } \\
\text { ROESY } \\
\text { correlations }\end{array}$ & $\begin{array}{c}\text { selected } \\
\text { HMBC } \\
\text { correlations }\end{array}$ \\
\hline $\mathrm{Ac}^{1}$ & 1 & 169.6 & & & $\underset{\text { Ac-2 }}{\text { Gln-NH }}$ \\
\hline \multirow[t]{4}{*}{ Gln $^{2}$} & $\begin{array}{l}2 \\
1\end{array}$ & $\begin{array}{r}22.8 \\
172.9\end{array}$ & 1.85 & Gln-NH & $\begin{array}{c}\text { Thr-NH, } \\
\text { Gln-2 }\end{array}$ \\
\hline & & $\begin{array}{l}52.4 \\
31.9\end{array}$ & $\begin{array}{l}4.40 \\
2.08 / 2.11\end{array}$ & Thr-NH & \\
\hline & 4 & 174.2 & & & Gln-3 \\
\hline & $\begin{array}{l}\mathrm{NH} \\
\mathrm{NH}_{2}\end{array}$ & & $\begin{array}{l}8.05 \\
7.21 / 6.72\end{array}$ & & \\
\hline \multirow[t]{4}{*}{$\mathrm{Thr}^{3}$} & 1 & 169.6 & & & $\begin{array}{l}\text { Leu-NH, } \\
\text { Thr-2 }\end{array}$ \\
\hline & 2 & 55.1 & 4.55 & Leu-NH & \\
\hline & 3 & 72.2 & 5.39 & $\begin{array}{l}\text { Leu-NH, } \\
\text { Ahp-NH }\end{array}$ & \\
\hline & $\begin{array}{l}4 \\
\mathrm{NH}\end{array}$ & 18.1 & $\begin{array}{l}1.17 \\
7.97\end{array}$ & & \\
\hline \multirow[t]{5}{*}{$\mathrm{Leu}^{4}$} & 1 & 170.6 & & & Ahp-NH \\
\hline & $\begin{array}{l}2 \\
3\end{array}$ & $\begin{array}{l}50.6 \\
39.1\end{array}$ & $\begin{array}{l}4.22 \\
1.68 / 1.30\end{array}$ & Ahp-NH & \\
\hline & 4 & 24.5 & $\begin{array}{l}1.00 / 1.00 \\
1.45\end{array}$ & & \\
\hline & 5 & $23.7 / 21.2$ & $0.84 / 0.73$ & & \\
\hline & $\mathrm{NH}$ & & 8.35 & Ahp-NH & \\
\hline \multirow[t]{7}{*}{$\mathrm{Ahp}^{5}$} & 1 & 169.3 & & & Ahp-2 \\
\hline & 2 & 48.9 & 3.64 & & \\
\hline & 3 & 22.0 & $2.40 / 1.55$ & & \\
\hline & 4 & 29.7 & $1.70 / 1.58$ & & \\
\hline & 5 & 74.1 & 5.07 & $\begin{array}{l}\text { Phe-3, } \\
\text { Phe-2'/6' }\end{array}$ & \\
\hline & $\mathrm{NH}$ & & 7.07 & & \\
\hline & $\mathrm{OH}$ & & 6.03 & Val-NH & \\
\hline \multirow[t]{7}{*}{$\mathrm{Phe}^{6}$} & 1 & 170.7 & & & $\begin{array}{c}\text { cmTyr- } \\
\mathrm{NCH}_{3}\end{array}$ \\
\hline & 2 & 50.7 & 4.72 & cmTyr-2 & \\
\hline & 3 & 35.8 & $2.89 / 1.83$ & & \\
\hline & $1^{\prime}$ & 136.9 & & & \\
\hline & $2^{\prime} / 6^{\prime}$ & 129.7 & 6.80 & & \\
\hline & $3^{\prime} / 5^{\prime}$ & 128.2 & 7.17 & & \\
\hline & $4^{\prime}$ & 126.6 & 7.13 & & \\
\hline \multirow[t]{11}{*}{$\mathrm{cmTyr}^{7}$} & 1 & 169.6 & & & $\begin{array}{l}\text { Val-NH, } \\
\text { cmTyr-2 }\end{array}$ \\
\hline & 2 & 61.0 & 4.90 & Val-NH & \\
\hline & 3 & 32.9 & $3.11 / 2.75$ & & \\
\hline & $1^{\prime}$ & 129.5 & & & \\
\hline & $2^{\prime}$ & 130.9 & 7.16 & & \\
\hline & $3^{\prime}$ & 120.0 & & & \\
\hline & $4^{\prime}$ & 152.3 & & & \\
\hline & $5^{\prime}$ & 117.0 & 6.99 & & \\
\hline & $6^{\prime}$ & 129.6 & 6.96 & & \\
\hline & $\mathrm{NCH}_{3}$ & 30.7 & 2.77 & Val-NH & \\
\hline & $\mathrm{OH}$ & & 10.1 & & \\
\hline \multirow[t]{5}{*}{$\mathrm{Val}^{8}$} & 1 & 172.3 & & & Thr-3 \\
\hline & 2 & 56.1 & 4.74 & & \\
\hline & 3 & 31.2 & 2.08 & & \\
\hline & 4 & 19.7/17.6 & $0.87 / 0.73$ & & \\
\hline & $\mathrm{NH}$ & & 7.42 & & \\
\hline
\end{tabular}

bond between these two amino acids, as reported for cyanopeptolins A-D, ${ }^{8}$ scyptolins A and $\mathrm{B},{ }^{12}$ hofmannolin, ${ }^{14}$ and A90720A. ${ }^{15}$ In the cyanopeptolins with cis amide bonds published before, the two amino acids that form the cis amide bond are N-Me-Phe and either Leu (cyanopeptolins $\mathrm{A}-\mathrm{D}^{8}$ ) or Thr (scyptolins $\mathrm{A}$ and $\mathrm{B}^{12}$ ), or the cis amide bonds are formed by N-Me-Tyr and either Leu (A90720A $\left.{ }^{15}\right)$ or $4^{\prime}-$ $\mathrm{O}-\mathrm{Me}$-Tyr in hofmannolin ${ }^{14}$ instead of $N$-methyl-(3'-chloro)Tyr and Phe in the new compound. In cyanopeptolin 954 all other amide bonds were trans, and the sequential NOEs are listed in Table 1 . The lactone ring closure between Thr-3 and Val-8 was verified by HMBC correlation from the $\beta$-proton of Thr-3 to the quaternary carbonyl $\mathrm{C}$ atom of Val-8. A common feature of many cyanopeptolins is the moiety located N-terminally from Thr-2. This moiety was composed of Gln and acetic acid. The acetylation of the $\alpha-\mathrm{NH}_{2}$ group of Gln was confirmed by the strong sequential

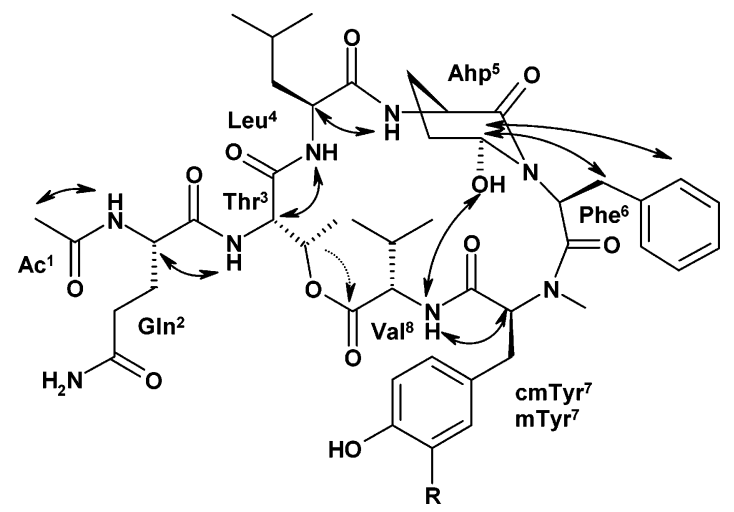

Figure 1. Chemical structure of cyanopeptolin $954(1, \mathrm{R}=\mathrm{Cl})$ and nostopeptin BN920 $(\mathbf{2}, \mathrm{R}=\mathrm{H})$. Double-headed arrows designate important ROESY correlations, and the dotted arrow indicates an HMBC correlation. mTyr, $N$-methyl-Tyr; cmTyr, 3 '-chloro- $N$-methylTyr.

NOE of the Gln-NH to the acetyl group (Table 1). Thus the gross structure was determined as $\mathbf{1}$.

The absolute configuration of cyanopeptolin 954 was determined by spectral and chemical methods. The stereochemistry of usual amino acids (Thr, Leu, Phe, and Val) was determined by chiral GC-MS amino acid analysis of the hydrolysate of $\mathbf{1}$, which allowed us to assign the L-configurations to all these amino acids. Upon acid hydrolysis, Gln was converted to Glu and determined to be the L-enantiomer, indicating the L-configuration of Gln. Oxidation of cyanopeptolin 954 with $\mathrm{CrO}_{3}{ }^{17}$ followed by acid-catalyzed hydrolysis led to the formation of L-Glu as the major degradation product of $\mathrm{Ahp}$, indicating the l-configuration of the $\alpha$-position of Ahp. The absolute stereochemistry of $(3 S, 6 R)$-L-Ahp was deduced from NOEs and corresponded to the configuration observed in other cyanopeptolines ${ }^{18}$ (see Supporting Information). The stereochemistry of chloro-N-Me-Tyr was investigated by HPLC analysis with Marfey's reagent ${ }^{19}$ and was determined to be the L-enantiomer. The inner ring current effect of the aromatic ring from $\mathrm{N}-\mathrm{Me}-\mathrm{Phe}$ or $\mathrm{N}-\mathrm{Me}-\mathrm{Tyr}$ induced a highfield shift to the $\beta$-, $\gamma$-, and $\delta$-protons of either Leu or Thr in those cyanopeptolins. ${ }^{8,12,14}$ This effect was also observed in cyanopeptolin 954, where H- $\beta^{\prime}$ of Phe- 6 had a normal shift of $2.89 \mathrm{ppm}$ but $\mathrm{H}-\beta^{\prime \prime}$ was shifted upfield to $1.83 \mathrm{ppm}$ and the aromatic protons $\mathrm{H} 2^{\prime} / 6^{\prime}$ of Phe- 6 were shifted upfield to $6.80 \mathrm{ppm}$. A strong characteristic NOE between Ahp- $\delta-\mathrm{OH}$ (5) and Val-NH (8) was detected in cyanopeptolin 954 and nostopeptin BN920, as well as in cyanopeptolins A-D, ${ }^{8}$ cyanopeptolin $\mathrm{S},{ }^{16}$ scyptolins A and $\mathrm{B},{ }^{12}$ and hofmannolin. ${ }^{14}$ This confirms the assumption of identical configurations of the amino acids in this part of the molecule. Therefore the amino acid $N$-methyl-( $3^{\prime}$ chloro)-Tyr is in the L-configuration.

The molecular formula of nostopeptin BN920 was deduced from the base peak of $\mathrm{ESI}^{+} \mathrm{MS}(\mathrm{m} / z$ 943.4537) yielding the molecular formula $\mathrm{C}_{46} \mathrm{H}_{64} \mathrm{~N}_{8} \mathrm{O}_{12} \mathrm{Na}$ with a deviation of $0.2 \mathrm{ppm}$ from the calculated exact mass. Therefore, uncharged nostopeptin BN920 has the molecular formula $\mathrm{C}_{46} \mathrm{H}_{64} \mathrm{~N}_{8} \mathrm{O}_{12}$. With the exception of $\mathrm{N}$-methylated 3 '-chloro-Tyr the same amino acids as in $\mathbf{1}$ were found in the ${ }^{1} \mathrm{H}$ and ${ }^{13} \mathrm{C} 2 \mathrm{D}$ NMR spectra of nostopeptin BN920 (data not shown). Instead of N-methylated 3'-chloro-Tyr, $\mathrm{N}$-methylated Tyr was detected. The amino acid sequence of nostopeptin BN920 was deduced from sequential NOEs and suggested this peptide to be identical to nostopeptin BN920. ${ }^{1}$ However, this peptide has not been reported in Microcystis before, and sequential NOEs unequivocally revealed a cis amide bond between Phe (6) and N-Me-Tyr 
(7) (Table 1). In Ploutno and Carmeli ${ }^{1}$ the amide bond between Phe (6) and N-Me-Tyr (7) is not defined in the text; however, the structure shows the trans-conformer. Our results suggest that the peptide isolated from Microcystis is a different conformer of nostopeptin BN920 and hence is named nostopeptin BN920 according to Ploutno and Carmeli. ${ }^{1}$ In this study all other amide bonds in nostopeptin BN920 were determined to be trans. The stereochemistry of the amino acids and of Ahp was found to be identical to those in $\mathbf{1}$. The stereochemistry of N-Me-l-Tyr was determined by HPLC analysis with Marfey's reagent. ${ }^{19}$ Similar to 1 the lactone ring closure between Thr-3 and Val-8 was verified by HMBC correlation, and the structure was determined as 2.

Cyanopeptolin 954 (1) and nostopeptin BN920 (2) inhibited bovine chymotrypsin with $\mathrm{IC}_{50}$ 's of 4.1 and $3.0 \mathrm{ng} \mathrm{mL}^{-1}$ (44.5 and $31.2 \mathrm{nM}$ ), respectively. Both compounds did not inhibit bovine trypsin at 15.9 and $10.6 \mu \mathrm{g} \mathrm{mL}-1$ (17.3 and $11.4 \mu \mathrm{M})$, respectively. Thus cyanopeptolin 954 and nostopeptin BN920 are among the strongest Ahp-containing chymotrypsin inhibitors. The strongest chymotrypsin inhibitor so far described is micropeptin T-20 with an $\mathrm{IC}_{50}$ of $2.5 \mathrm{nM},{ }^{4}$ while the majority of cyanopeptolins exhibit $\mathrm{IC}_{50}$ values of $2-4 \mu \mathrm{M}$. Among the heptadepsipeptides of Microcystis inhibition of trypsin or chymotrypsin is mutually exclusive. Compounds that display inhibitory activity against trypsin but not against chymotrypsin (cyanopeptolin $\mathrm{A},{ }^{20}$ micropeptins $\mathrm{A}$ and $\mathrm{B},{ }^{9}$ micropeptin SF995, ${ }^{21}$ micropeptins SD944 and SD999, ${ }^{5}$ micropeptins EI964 and EI992 22 ) are characterized by a basic amino acid in position 4, while heptadepsipeptides that inhibit chymotrypsin but not trypsin (micropeptin 88A,,$^{23}$ micropeptins SD979 and SD1002, ${ }^{5}$ cyanopeptolin 963A, ${ }^{11}$ cyanopeptolins 954 and 920, this study) are characterized by a neutral (Leu) or aromatic (Phe, Tyr) amino acid in position 4 . This corresponds to the known specificity of chymotrypsin (preferred cleavage of peptide bonds at Phe and Tyr) and trypsin (cleavage at Lys or Arg). Trypsins and chymotrypsins have recently been shown to be the major digestive proteases in the most important natural grazer of Microcystis, ${ }^{24}$ and it remains to be tested if the natural grazing pressure drives the evolution of new variants of depsipeptides in natural ecosystems.

\section{Experimental Section}

General Experimental Procedures. Optical rotations were determined on a Perkin-Elmer 241 polarimeter using a quartz cell of $10 \mathrm{~cm}$ length and $1 \mathrm{~mL}$ volume. UV spectra were recorded on a Cary 50 photometer (Varian). NMR spectra were recorded on a Bruker DMX500 (Bruker-Daltonics, Fällanden, Switzerland) spectrometer using a triple inverse probe for the $1 \mathrm{D}-{ }^{1} \mathrm{H}$ and $2 \mathrm{D}$ spectra. The sample concentration was $0.5-1$ $\mathrm{mM}$ in DMSO- $d_{6} .{ }^{1} \mathrm{H}$ and ${ }^{13} \mathrm{C}$ shifts are referred to DMSO- $d_{6}$ $=2.49$ and $39.9 \mathrm{ppm}$, respectively The following NMR experiments were carried out: $1 \mathrm{D}-{ }^{1} \mathrm{H},{ }^{1} \mathrm{H}-{ }^{1} \mathrm{H}-\mathrm{COSY},{ }^{1} \mathrm{H}-{ }^{1} \mathrm{H}-\mathrm{ROESY}$, ${ }^{1} \mathrm{H}-{ }^{1} \mathrm{H}$-TOCSY, ${ }^{1} \mathrm{H}-{ }^{13} \mathrm{C}-\mathrm{COSY}$ (HSQC). A Bruker DRX500 with TXI-CryoProbe was used for the ${ }^{1} \mathrm{H}-{ }^{13} \mathrm{C}$-long-range COSY (HMBC) and a DRX400 with ${ }^{13} \mathrm{C}$ CryoProbe for the ${ }^{13} \mathrm{C}$ spectra. ESIMS spectra were recorded in positive and negative ion mode, using a 9.4 T Apex-III FT-MS (Bruker Daltonics, Fällanden, Switzerland). HPLC-ESI-MS-derived mass spectra were obtained on a LC-MS (LCQ Duo mass spectrometer, Finnigan Thermoquest) equipped with an electrospray source (ESI). The composition of the derivatized hydrolysate was determined using GC-MS (Finnigan GCQ). HPLC separations were performed on a Shimadzu 10AVP system equipped with a diode array detector and an autosampler.

Culture of Microcystis. M. aeruginosa NIVA Cya 43 (Culture Collection of Algae, Norwegian Institute for Water
Research) was grown in $10 \mathrm{~L}$ glass bottles in mineral medium ${ }^{25}$ with aeration (filtered, $0.3 \mathrm{~L} \mathrm{~min}^{-1}$, without additional $\mathrm{CO}_{2}$ ). Cultures were illuminated continuously with fluorescent tubes at an intensity of $60 \mu \mathrm{mol} \mathrm{m}{ }^{-2} \cdot \mathrm{s}^{-1}$ at $20{ }^{\circ} \mathrm{C}$ for $20-30$ days. Then cells were harvested by centrifugation $(4.000 \mathrm{~g})$, lyophilized, and kept in a freezer at $-20{ }^{\circ} \mathrm{C}$ until extraction.

Extraction and Isolation. Portions of the lyophilized cyanobacterial biomass ( $1 \mathrm{~g}$ ) were extracted with $\mathrm{MeOH}$ (100 $\mathrm{mL}$ ) for $12 \mathrm{~h}$ in the dark, and the extract was separated by centrifugation from the residue. The supernatant was diluted with ultrapure water to a $10 \%$ methanol solution and was allowed to pass under vacuum through an equilibrated reversedphase ODS cartridge (10 g sorbent; Varian, Darmstadt, Germany). Material retained on the cartridge was eluted in steps with $50 \mathrm{~mL}$ each of $20,40,60$, and $80 \%$ methanol in water and finally with $100 \%$ methanol. The fraction eluting with $60 \%$ methanol from the cartridge was evaporated in a vacuum rotary evaporator at $40{ }^{\circ} \mathrm{C}$. The residue was dissolved in $50 \%$ methanol $(1 \mathrm{~mL})$ and fractionated by reversed-phase HPLC (Nucleosil 150-5 C18, $250 \times 4 \mathrm{~mm}$, Macherey-Nagel,

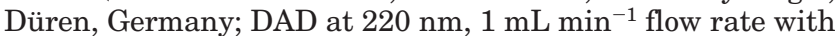
$33 \%$ solvent $\mathrm{B}$; solvent $\mathrm{A}: \mathrm{H}_{2} \mathrm{O}$ and $0.05 \%$ TFA; solvent $\mathrm{B}: 90$ : 10 acetonitrile/water and $0.05 \%$ TFA). The peaks eluting at 8.8 and 12.7 min were collected in about 50 HPLC runs. Subsequently the collected volume was diluted with the same volume of $\mathrm{H}_{2} \mathrm{O}$ and applied to an ODS cartridge (Varian, equilibrated with $20 \% \mathrm{MeOH}$ ). The cartridge was washed with $5 \% \mathrm{MeOH}$ to neutral $\mathrm{pH}$; the inhibitors were eluted with 50 $\mathrm{mL}$ of $\mathrm{MeOH}$, evaporated to dryness, and dissolved in $\mathrm{MeOH}$ $(1 \mathrm{~mL})$ to obtain 1 in $0.32 \%$ and $\mathbf{2}$ in $0.16 \%$ yield based on the dry weight of the cyanobacterium.

Analysis of the Hydrolysate. The amino acids of the peptides were determined with GC-MS after hydrolysis of 100 $\mu \mathrm{g}$ of each highly purified cyanopeptolin in $6 \mathrm{M} \mathrm{HCl}$ at $110^{\circ} \mathrm{C}$ for $48 \mathrm{~h}$. The derivatization of the dried hydrolysate and of equivalent amounts of amino acid standards was performed with MTBSTFA in tetrahydrofurane and TFA (20:25:0.05) according to Blom et al. ${ }^{26}$ Analyses were conducted on a capillary column (30 m DB-1301, $0.32 \mathrm{~mm}$ i.d., $0.25 \mu \mathrm{m}$ film thickness under the following separation conditions: $1 \mathrm{~min}$ at $120^{\circ} \mathrm{C}, 120$ to $250{ }^{\circ} \mathrm{C}$ at a rate of $10{ }^{\circ} \mathrm{C} \mathrm{min}-1$. The retention times ( $\mathrm{min}$ ) of amino acid standards were as follows: Val (9.84), Leu (10.35), Glu (16.22), Thr (13.58), Phe (14.42), N-MeTyr (17.12), 3'-chloro-N-MeTyr (19.55).

To determine the configuration of the amino acids, the hydrolysate was dried and subsequently acylated with trifluoroacetic acid anhydride (Fluka, Buchs, Switzerland) at 80 ${ }^{\circ} \mathrm{C}$ for $1 \mathrm{~h}$. Analyses were conducted on a Chirasil-Val column (Permabond-L-Chirasil-Val; $25 \mathrm{~m} \times 0.25 \mathrm{~mm}$; Macherey-Nagel, Düren, Germany) under the following separation conditions: $2 \mathrm{~min}$ at $80^{\circ} \mathrm{C}, 80$ to $180^{\circ} \mathrm{C}$ at the rate of $8^{\circ} \mathrm{C} \mathrm{min}-1,10 \mathrm{~min}$ at $180{ }^{\circ} \mathrm{C}$. The retention times $(\mathrm{min})$ of enantiomeric amino acids on the Chirasil Val column were as follows: D-Val (6.54), L-Val (6.64), D-Thr (6.86), l-Thr (6.98), D-Leu (8.71), L-Leu (8.92), D-Glu (13.64), L-Glu (13.72), D-Phe (14.81), L-Phe (14.87). The determination of the absolute configuration of each amino acid was confirmed by spiking the derivatized hydrolysates with the derivatized authentic amino acids.

Oxidation of Cyanopeptolin 954 and Nostopeptin BN920 by $\mathrm{CrO}_{3} \cdot \mathrm{CrO}_{3}$ oxidation was performed according to Itou et al. ${ }^{17}$ Compound 1 or $\mathbf{2}(30 \mu \mathrm{g})$ was dissolved in $500 \mu \mathrm{L}$ of a solution of $\mathrm{CrO}_{3}$ in ethanol $\left(1 \mathrm{mg} \mathrm{mL} \mathrm{mL}^{-1}\right)$ and stirred at room temperature for $2 \mathrm{~h}$. Then $500 \mu \mathrm{L}$ of ultrapure water was added and the sample stored at $4{ }^{\circ} \mathrm{C}$ for $12 \mathrm{~h}$. Subsequently the sample was filled up to $10 \mathrm{~mL}$ with $90 / 10$ water/ethanol and subjected to an ODS cartridge (Varian, equilibrated with $10 \% \mathrm{MeOH} ; \mathrm{v} / \mathrm{v})$. The cartridge was flushed with $10 \% \mathrm{MeOH}$ and the sample eluted with $100 \% \mathrm{MeOH}$. The eluate was evaporated to dryness $\left(40{ }^{\circ} \mathrm{C}\right)$ and hydrolyzed as described above. Glu that was obtained after hydrolysis allowed the determination of the configuration of the $\alpha$-position of Ahp.

Synthesis of N-Me-L-Tyr. $N$-methyl-L-tyrosine was prepared according to a slightly modified protocol. ${ }^{27} \mathrm{~N}$-Benzyl-Ltyrosine: To a stirred solution of $9.06 \mathrm{~g}$ (50 mmol) of L-tyrosine in $30 \mathrm{~mL}$ of a $4 \mathrm{M}$ aqueous sodium hydroxide solution was 
added $5 \mathrm{~mL}$ ( $50 \mathrm{mmol})$ of freshly distilled benzaldehyde as a single portion. After $30 \mathrm{~min}$ of stirring, the mixture became homogeneous and $570 \mathrm{mg}(150 \mathrm{mmol})$ of sodium borohydride was added carefully in small portions, keeping the temperature below $15{ }^{\circ} \mathrm{C}$. After stirring for another $30 \mathrm{~min}$ the same procedure was repeated with the above given amounts of benzaldehyde and sodium borohydride. After stirring for an additional $2 \mathrm{~h}$, the reaction mixture was extracted two times with $30 \mathrm{~mL}$ of diethyl ether each and neutralized with $1 \mathrm{M}$ aqueous hydrochloric acid to give a precipitate. The crude $\mathrm{N}$-benzyl-L-tyrosine was filtered off, washed with water, dried under vacuum (yield 88\%), and used for the methylation without further purification. $N$-Benzyl- $N$-methyl-L-tyrosine: $5.15 \mathrm{~g}(20 \mathrm{mmol})$ of finely powdered $N$-benzyl-L-tyrosine was treated with a mixture of $2.3 \mathrm{~mL}(60 \mathrm{mmol})$ of formic acid and $2 \mathrm{~mL}(24 \mathrm{mmol})$ of aqueous formaldehyde solution (38-40\%) at $100{ }^{\circ} \mathrm{C}$. After $3 \mathrm{~h}$ the reaction was finished as monitored by TLC. Evaporation to dryness and recrystallization of the residue from water/ethanol gave the desired compound as a colorless solid (yield: $78 \%$ ). $N$-Methyl-L-tyrosine: A solution of $4 \mathrm{~g}$ (14.7 mmol) of $N$-benzyl- $N$-methyl-L-tyrosine was dissolved in $60 \mathrm{~mL}$ of a mixture consisting of $58 \mathrm{~mL}$ of glacial acetic acid and $2 \mathrm{~mL}$ of concentrated hydrochloric acid. The mixture was hydrogenated with $200 \mathrm{mg}$ of palladium on charcoal (5 mol \% Pd). After hydrogenation the catalyst was filtered off and the solution was evaporated to dryness. Recrystallization from water/ethanol gave the desired compound in $71 \%$ yield, $[\alpha]{ }^{20} \mathrm{D}+30.4[c 1,1: 16 \mathrm{M} \mathrm{HCl} / \mathrm{HOAc}(\mathrm{v}$ : $\mathrm{v})$ ].

Synthesis of 3'-Chloro-N-Me-Tyr. N-Me-D-Tyr was obtained from Bachem (Bubendorf, Switzerland). A mixture of $60 \mathrm{mg}$ of N-Me-D-Tyr or N-Me-L-Tyr and $1 \mathrm{~mL}$ of freshly distilled sulfuryl chloride was warmed at $80{ }^{\circ} \mathrm{C}(3 \mathrm{~min})$ according to Ishida et al. ${ }^{13}$ until gas no longer evolved. Then $2 \mathrm{~mL}$ of sulfuryl chloride was added and warmed at $80{ }^{\circ} \mathrm{C}(1$ h). Thereafter, excess sulfuryl chloride was removed by evaporation and freeze-drying.

HPLC Analysis of N-Me-Tyr and chloro-N-Me-Tyr. The enantiomers of N-Me-Tyr and chloro-N-Me-Tyr were determined by HPLC using Marfey's method. ${ }^{19}$ To the acid hydrolysate $\left(6 \mathrm{M} \mathrm{HCl}\right.$ at $110{ }^{\circ} \mathrm{C}$ for $24 \mathrm{~h}$ ) of $100 \mu \mathrm{g}$ of $\mathbf{1}$ or 2 was added $50 \mu \mathrm{L}$ of 1-fluoro-2,4-dinitrophenyl-5-L-alanineamide (L-FD$\mathrm{AANaHCO}_{3}, \mathrm{Novabiochem}$, Läufelfingen, Switzerland) in acetone $\left(10 \mathrm{mg} \mathrm{mL}^{-1}\right)$. The mixtures were heated at $80{ }^{\circ} \mathrm{C}$ for 3 min. After cooling, $120 \mu \mathrm{L}$ of $1 \mathrm{M} \mathrm{HCl}$ and $300 \mu \mathrm{L}$ of $50 \%$ acetonitrile were added. The derivatives were analyzed on a C-18 Supelco-Sil ODS reversed-phase column $(4.6 \times 250 \mathrm{~mm}$; Supelco; Bellefonte, PA); the mobile phase was acetonitrile/ $\mathrm{H}_{2} \mathrm{O} /$ trifluoroacetic acid (23/77/0.05; v/v/v). The retention times of standards ( $\mathrm{min}$ ) were as follows: N-Me D-Tyr L-FDAA (29.7 min), N-Me L-Tyr L-FDAA (30.2 min), chloro-N-Me D-Tyr L-FDAA (49.8 $\mathrm{min}$ ), and chloro-N-Me L-Tyr L-FDAA (51.9 min). The retention times of N-Me Tyr L-FDAA in the acid hydrolysate of nostopeptin BN920 was $30.3 \mathrm{~min}$, and that of chloro$\mathrm{N}-\mathrm{Me}$ Tyr L-FDAA in the acid hydrolysate of cyanopeptolin 954 was $51.8 \mathrm{~min}$.

Molar Absorption Coefficient. The molar absorption coefficient was determined by quantitative analysis of L-Leu after acidic hydrolysis of $\mathbf{1}$ and $\mathbf{2}$. L-U- ${ }^{13} \mathrm{C}_{6}$ Leu (Euriso-top, Saarbrücken, Germany) was added as an internal standard before hydrolysis. After derivatization with MTBSTFA and GC-EIMS, the integrals of the fragment ions $\mathrm{m} / \mathrm{z} 200,274,302$, and 360 were used for quantitative analysis of Leu and $\mathrm{m} / \mathrm{z}$ 205, 279, 308, and 366 for the ${ }^{13} \mathrm{C}$-labeled Leu. These values were correlated to the UV absorption of $\mathbf{1}$ and $\mathbf{2}$ measured before hydrolysis.

Inhibition of Proteases. The inhibition of trypsin and chymotrypsin was measured according to Von Elert et al. ${ }^{24}$ Solutions of $N$ - $\alpha$-benzoyl-DL-arginine 4-nitroanilide hydrochloride (Sigma, $187 \mu \mathrm{M}$ ) and $N$-succinyl-L-alanyl-L-alanyl-L-prolylL-phenylalanine 4-nitroanilide (Sigma, $125 \mu \mathrm{M}$ ) in potassium phosphate buffer ( $0.1 \mathrm{M}, \mathrm{pH} 7.5)$ were used as substrates for both trypsin (T-4665, Sigma) and $\alpha$-chymotrypsin (C-4129, Sigma) from bovine pancreas. The absorption change was measured for $5 \mathrm{~min}$ at $20{ }^{\circ} \mathrm{C}$ at $390 \mathrm{~nm}$ in $1 \mathrm{~mL}$ with a Cary 50 photometer.

Cyanopeptolin 954 (1): amorphous powder; UV (MeOH) $\lambda_{\max } 282(\epsilon 2000) \mathrm{nm} ;{ }^{1} \mathrm{H}$ and ${ }^{13} \mathrm{C}$ NMR, see Table 1 ; ESIMS (positive mode) $\mathrm{m} / z$ 976.9 (100\%), 497.2 (80\%), 936.9 (20-25\%), $940.8(20-25 \%), 993.9,489.3$; ESIMS (negative mode) $\mathrm{m} / \mathrm{z}$ 250.1 (100\%), 953.0 (20\%), 988.9 (15\%); HRESIMS (positive) $\mathrm{m} / z$ 977.4141 $\left(\mathrm{C}_{46} \mathrm{H}_{63} \mathrm{~N}_{8} \mathrm{O}_{12} \mathrm{ClNa}\right.$, relative mass error $\Delta_{\mathrm{m}}=0.5$ ppm).

Nostopeptin BN920 (2): amorphous powder; UV (MeOH) $\lambda_{\max } 279(\epsilon 1600) \mathrm{nm}$; ESIMS (positive mode) $\mathrm{m} / \mathrm{z} 942.9(100 \%)$, 480.4 (50\%), 903.0 (10-15\%), 940.8, 958.9, 472.2, ESIMS (negative mode) $\mathrm{m} / \mathrm{z} 250.1$ (100\%), 919.1 (20\%), 955.0 (15\%); HRESIMS (positive) $\mathrm{m} / z$ $943.4537\left(\mathrm{C}_{46} \mathrm{H}_{64} \mathrm{~N}_{8} \mathrm{O}_{12} \mathrm{Na}\right.$, relative mass error $\Delta_{\mathrm{m}}=0.5 \mathrm{ppm}$ ).

Acknowledgment. Technical and scientific advice during the chemical analysis and helpful comments on an earlier version of this paper by F. Jüttner are deeply acknowledged. The technical assistance of C. Gebauer is gratefully acknowledged. The authors are indebted to C. Guenat for providing the HR-MS data. We thank Y. Shimizu and an anonymous reviewer for helpful comments on an earlier version of the paper.

Supporting Information Available: NMR data of 3-amino-6hydroxy-2-piperidone (Ahp) in previously published depsipeptides. This material is available free of charge via the Internet at http://pubs.acs.org.

\section{References and Notes}

(1) Ploutno, A.; Carmeli, S. Tetrahedron 2002, 58, 9949-9957.

(2) Carmichael, W. W. J. Appl. Bacteriol. 1992, 72, 445-459.

(3) Agrawal, M. K.; Bagchi, D.; Bagchi, S. N. Hydrobiologia 2001, 464 $37-44$.

(4) Okano, T.; Sano, T.; Kaya, K. Tetrahedron Lett. 1999, 40, 2379-2382.

(5) Reshef, V.; Carmeli, S. Tetrahedron 2001, 57, 2885-2894.

(6) Harada, K. I.; Mayumi, T.; Shimada, T.; Suzuki, M.; Kondo, F.; Watanabe, M. F. Tetrahedron Lett. 1993, 34, 6091-6094.

(7) Murakami, M.; Kodani, S.; Ishida, K.; Matsuda, H.; Yamaguchi, K Tetrahedron Lett. 1997, 38, 3035-3038.

(8) Martin, C.; Oberer, L.; Ino, T.; Koenig, W. A.; Busch, M.; Weckesser, J. J. Antibiot. 1993, 46, 1550-1556.

(9) Okino, T.; Murakami, M.; Haraguchi, R.; Munekata, H.; Matsuda, H.; Yamaguchi, K. Tetrahedron Lett. 1993, 34, 8131-8134.

(10) Tsukamoto, S.; Painuly, P.; Young, K. A.; Yang, X.; Shimizu, Y. J. Am. Chem. Soc. 1993, 115, 11046-11047.

(11) Bister, B.; Keller, S.; Baumann, H.; Nicholson, G.; Weist, S.; Jung, G.; Süssmuth, R. D.; Jüttner, F. J. Nat. Prod. 2004, 67, 1755-1757.

(12) Matern, U.; Oberer, L.; Falchetto, R. A.; Erhard, M.; Koenig, W. A.; Herdman, M.; Weckesser, J. Phytochemistry 2001, 58, 1087-1095.

(13) Ishida, K.; Matsuda, H.; Murakami, M.; Yamaguchi, K. J. Nat. Prod. 1997, 60, 184-187.

(14) Matern, U.; Oberer, L.; Erhard, M.; Herdman, M.; Weckesser, J. Phytochemistry 2003, 64, 1061-1067.

(15) Bonjouklian, R.; Smitka, T. A.; Hunt, A. H.; Occolowitz, J. L.; Perun T. J.; Doolin, L.; Stevenson, S.; Knauss, L.; Wijayaratne, R.; Szewczyk, S.; Patterson, G. M. L. Tetrahedron 1996, 52, 395-404.

(16) Jakobi, C.; Oberer, L.; Quiquerez, C.; Koenig, W. A.; Weckesser, J. FEMS Microbiol. Lett. 1995, 129, 129-133.

(17) Itou, Y.; Ishida, K.; Shin, H. J.; Murakami, M. Tetrahedron 1999, $55,6871-6882$.

(18) Matern, U.; Schleeberger, C.; Jelakovic, S.; Weckesser, J.; Schulz, G. Chem. Biol. 2003, 10, 997-1001.

(19) Harada, K. I.; Fujii, K.; Mayumi, T.; Hibino, Y.; Suzuki, M. Tetrahedron Lett. 1995, 36, 1515-1518.

(20) Weckesser, J.; Martin, C.; Jakobi, C. Syst. Appl. Microbiol. 1996, 19 $133-138$.

(21) Banker, R.; Carmeli, S. Tetrahedron 1999, 55, 10835-10844.

(22) Ploutno, A.; Shoshan, M.; Carmeli, S. J. Nat. Prod. 2002, 65, 973978.

(23) Ishida, K.; Matsuda, H.; Murakami, M. Tetrahedron 1998, 54, 55455556.

(24) Von Elert, E.; Agrawal, M. K.; Gebauer, C.; Jaensch, H.; Bauer, U. Zitt, A. Comp. Biochem. Physiol. B 2004, 137, 287-296.

(25) Jüttner, F.; Leonhardt, J.; Möhren, S. J. Gen. Microbiol. 1983, 129 407-412.

(26) Blom, J. F.; Bister, B.; Bischoff, D.; Nicholson, G.; Jung, G.; Süssmuth, R. D.; Jüttner, F. J. Nat. Prod. 2003, 66, 431-434.

(27) Quitt, P.; Hellerbach, J.; Vogler, K. Helv. Chim. Acta 1963, 46, $327-333$

NP050079R 